\title{
New Solution to Nonlinear, Dynamic, Systematic Problems in Statistical Physics by Control Theory in Engineering Science
}

\author{
Deok-Soo Cha ${ }^{1}$ and Hee-Jong Jun ${ }^{1}$ \\ ${ }^{1}$ Soongsil University
}

April 28, 2020

\begin{abstract}
This paper presents as advanced solution for nonlinear, dynamic, systematical problems involving complexity, multidisciplinary sciences, such as prediction of stock prices, food chain in ecological systems, and mechanical disturbances. This study proposes an idea for a systematical solution to these problems. Most scientist misunderstand it as a black box, but it can be solve based on the control theory of engineering science; hence, it is not different from the old chaos theory, moreover, are not relevant to determinism. However, the chaos theory developed by classical physics in the 17th century, it is a banal and degenerate theory because it was developed new solution in the 20th century by engineers. Nevertheless, physicists do not welcome the advanced solution because it is against determinism. Hence, it is separated from physics and adopted by engineering science. Scientists can apply either solution to their discipline. To prove this solution, four application examples, such as Kuhn's innovation theory and Lorenz's butterfly effect, are provided.
\end{abstract}

\section{Hosted file}

advance_eng2004(50)main.pdf available at https ://authorea.com/users/314079/articles/444471-newsolution-to-nonlinear-dynamic-systematic-problems-in-statistical-physics-by-control-theoryin-engineering-science 